\title{
Pulmonary Artery
}

\section{Leiomyosarcoma Diagnosed without Delay}

\author{
Motohisa Yamasakia, ${ }^{a}$ Yuki Sumi ${ }^{a}$ Yumi Sakakibara $^{a}$ \\ Meiyo Tamaoka ${ }^{a}$ Yasunari Miyazaki ${ }^{a}$ Hirokumi Arai ${ }^{c}$ \\ Katsuo Kojimac Fusahiko Itoh ${ }^{c}$ Tomonari Amano $^{d}$ \\ Yasuyuki Yoshizawa ${ }^{a}$ Naohiko Inase $^{a}$
}

aDepartment of Integrated Pulmonology, Graduate School of Medical and Dental Science, Tokyo Medical and Dental University, 'bepartment of Internal Medicine, Nakano General Hospital, and Departments of ${ }^{\circ}$ Cardiovascular Surgery and ${ }^{\mathrm{d} H u m a n}$ Pathology, Graduate School of Medical and Dental Science, Tokyo Medical and Dental University, Tokyo, Japan

\section{Key Words}

Pulmonary artery sarcoma - Leiomyosarcoma - Intimal sarcoma - Tumor emboli . Pulmonary thromboembolism · FDG-PET

\begin{abstract}
A 63-year-old female presented with abnormal lung shadows but had, apart from this, few symptoms. Computed tomography (CT) revealed multiple nodules and blockage of the pulmonary artery. She was immediately diagnosed with pulmonary artery sarcoma based on a careful differential diagnosis and underwent surgery. Her tumor was pathologically diagnosed as leiomyosarcoma (i.e. intimal sarcoma). Pulmonary artery sarcoma can be easily confounded with thromboembolism in a clinical setting and some cases are diagnosed post mortem only. In our case, clinical prediction scores (Wells score, Geneva score, and revised Geneva score) for the pulmonary embolism showed low probability. Moreover, chest CT showed uncommon findings for pulmonary thromboembolism, as the nodules were too big for thrombi. Because surgical resection can provide the only hope of long-term survival in cases of pulmonary artery sarcoma, clinicians should consider this possibility in the differential diagnosis of pulmonary embolism. Clinical prediction scores and CT findings might help to reach the correct diagnosis of pulmonary artery sarcoma.
\end{abstract}




\section{Introduction}

Primary pulmonary artery sarcomas are very rare and aggressive neoplasms. Morphologically, there are at least ten reported subtypes of pulmonary artery sarcoma: undifferentiated sarcoma, leiomyosarcoma, rhabdomyosarcoma, fibrosarcoma, myxosarcoma, malignant mesenchymoma, chondrosarcoma, angiosarcoma, osteosarcoma, and malignant fibrous histiocytoma $[1,2]$. The tumors appear to arise from multipotential mesenchymal cells of the bulbus cordis $[2,3]$. There is evidence that the intima of the small arteries contain primitive mesenchymal cells with potential for multidirectional differentiation [4].

Leiomyosarcoma is a malignant tumor composed of smooth-muscle cells. The most common locations of soft tissue leiomyosarcoma are the retroperitoneal and the pelvic region. Another distinctive subgroup consists of leiomyosarcomas that arise in large blood vessels, most commonly the inferior vena cava and the large veins of the lower extremities. Arterial origin has been observed, but is rare; sarcomas of the pulmonary artery and other large arteries have distinct features and are better classified as intimal sarcomas $[5,6]$.

Primary pulmonary artery sarcoma is easily confounded with pulmonary thromboembolism in a clinical setting. Many patients initially receive anticoagulant therapy but fail to respond, and many are diagnosed post mortem only. We report a case of pulmonary intimal sarcoma that could be promptly diagnosed by careful consideration of the differential diagnosis.

\section{Case Report}

A 63-year-old female was admitted to our hospital after abnormal lung shadows were discovered during a routine annual medical checkup. Two months before her admission, she had experienced 1 episode of slight chest tightness. She was a housewife who had never smoked. Thirteen years previously, she had been diagnosed with rheumatoid arthritis and had been taking prednisolone (1 $\mathrm{mg})$ and salicylazosulfapyridine for 10 years and methotrexate for 4 years. Her vital signs on admission were a temperature of $36.7^{\circ} \mathrm{C}$, a blood pressure of $127 / 90 \mathrm{~mm} \mathrm{Hg}$, a pulse of 84 beats per minute, and an oxygen saturation measured by pulse oximeter $\left(\mathrm{SpO}_{2}\right)$ of $94.3 \%$. On physical examination she presented with ulnar drift deformities in fingers of both hands. Her lungs were clear on auscultation and her cardiac sound was a regular rhythm without heart murmur. Laboratory findings indicated slight inflammation, with a white blood cell count of 9,300 per microliter and C-reactive protein of $2.3 \mathrm{mg} / \mathrm{dl}$ (table 1). The results of arterial blood gas were as follows: $\mathrm{pH}, 7.429$; partial pressure for oxygen $\left(\mathrm{PaO}_{2}\right)$, $69.3 \mathrm{~mm} \mathrm{Hg}$; partial pressure for carbon dioxide $\left(\mathrm{PaCO}_{2}\right), 38.4 \mathrm{~mm} \mathrm{Hg}$; bicarbonate content $\left(\mathrm{HCO}_{3}^{-}\right)$, $25.0 \mathrm{mEq} / \mathrm{l}$. Tumor markers inluding carcinoembryonic antigen (CEA), cytokeratin fragment 19 (CYFRA), pro-gastrin releasing peptide (ProGRP), sialyl Lewis X-i antigen (SLX), squamous cell carcinoma antigen (SCC), and neuron-specific $\gamma$-enolase (NSE), were within normal limits. Electrocardiography revealed a right atrial enlargement. Chest radiography showed a mass in the left upper lung field (fig. 1a) and reduced blood vessel distribution in the left lower lung field. Computed tomography (CT) scanning of the chest revealed multiple nodules in the left lung (fig. lb, c) and lowdensity lesions occupying the pulmonary artery (fig. 1d). In magnetic resonance imaging (MRI), mass lesions with a low-density appearance in T1-weighted images and high-density appearance in T2weighted images were spread across the pulmonary arteries in the left upper lobe (fig. 2a, b). Lung perfusion scintigraphy revealed perfusion defect in the left whole lung and focal perfusion defect in the right lung (fig. 2c). F-18-2-fluoro-2-deoxyglucose positron emission tomography (FDG-PET) showed multiple mass lesions in the lung fields and mediastinum (fig. 2d, e). The maximal standard uptake value (SUVmax) was 2.6. Transthoracic echocardiography revealed pulmonary hypertension (the predicted right ventricular systolic pressure was $49 \mathrm{~mm} \mathrm{Hg}$ ) with pulmonary artery dilation, moderate pulmonic valve regurgitation, moderate tricuspid valve regurgitation, mild mitral valve regurgitation, 
dilation of the left atrium, right atrium and right ventricle, and concentric left ventricular hypertrophy (fig. 2f). In flexible bronchoscopy, the trachea and left main bronchus were slightly pressed rightward. The mucosa in the upper division of the left upper lobe was irregular, suggesting tumor invasion. The pulmonary trunk was difficult to detect by endobronchial ultrasonography (EBUS), but the EBUS examination clearly showed a tumorous mass within the left pulmonary artery. A high risk of complications prevented us from biopsying the mass intravascularly.

We decided to intervene surgically, as the findings suggested a diagnosis of primary pulmonary artery sarcoma rather than a pulmonary embolism. Exploration of the pulmonary artery under cardiopulmonary bypass revealed a tumor in the left pulmonary artery with a thickened arterial wall invaded by the tumor. The anterior walls of both the main and right pulmonary arteries were resected as much as possible and reconstructed with an autologous pericardial patch with a 5-0 monofilament continuous suture. The tumor had infiltrated the right distal pulmonary artery, which prevented any attempt of complete tumor resection under the guidance of intraoperative pathological diagnosis. A left lobectomy was performed thereafter.

The gross section (fig. 3a) of the tumor was clear ivory-white with necrosis and hemorrhage. The left pulmonary artery was dilated to $2.5 \mathrm{~cm}$ in width by an intraluminal tumor $(6.5 \times 2.5 \times 2.5 \mathrm{~cm})$ that extended through the pulmonary arteries into the distal lung parenchyma. There was a contiguous welldefined $3.5 \mathrm{~cm}$ mass consisting of several nodules in the lung. Several nodules in the left upper lobe remained within the pulmonary arteries, but most of the tumors extended into the lung parenchyma, forming an ill-defined mass. The tumor in the lower lobe extended mainly through the pulmonary artery and formed an ill-defined $2.5 \mathrm{~cm}$ mass at the superior segment in the lower lobe. Patchy pulmonary infarction lesions spread across both the upper and lower lobes.

Microscopically, the tumor was composed of spindle- or circular-shaped cells with cigar-shaped nuclei and elongated cytoplasm (fig. 3b). Two patterns of tumor growth were observed in the lung parenchyma: some tumors extended into the alveolar septum and interalveolar septum, forming a reticular pattern, while others grew solidly within the alveolar space. Tumor embolisms with cavities and necrosis surrounded by viable tumor cells were observed in both the upper and lower lobes. A fungal abscess of $15 \times 5 \mathrm{~mm}$ in size, possibly aspergillus, was connected to the bronchioles in the left superior lobe anterior segment. No pathological lesions suggestive of pulmonary thromboembolism were evident. Immunohistochemical staining for alpha smooth muscle actin ( $\alpha$-SMA) and desmin, two markers for mesenchymal neoplasms, were focally positive in the pleomorphic cancer cells (fig. $3 \mathrm{c}, \mathrm{d}$ ). Immunohistochemical staining for CD99 was partially positive in the spindle cancer cells. Immunohistochemical staining for CD31 PECAM-1, CD34 (endothelial cell marker), myosin, CD57, S100, and epithelial markers (including cytokeratins; CAM5.2, AE1/AE3, CK7, CK19) and EMA (epithelial membrane antigen) were negative. Immunohistochemical staining for BCL-2 was positive and the Ki-67 labeling index (the percentage of positive cells stained with proliferation marker Ki-67 antibody) was $40 \%$ (fig. 3e), suggesting that the tumor had aggressive characteristics. The patient was diagnosed with primary pulmonary artery sarcoma with smooth muscle differentiation compatible with leiomyosarcoma (i.e. intimal sarcoma). Complete tumor resection was impossible, and the patient had developed an aplastic anemia that prevented us from administering other therapies. The tumor in the right pulmonary artery gradually grew and metastasized to the liver. The patient died 14 months after the operation.

\section{Discussion}

Primary pulmonary artery sarcomas are very rare tumors: no more than about 150 cases have been reported in English-language literature [1-3, 7, 8]. The differential diagnoses include pulmonary artery sarcoma, thromboembolism, and lung cancer. The symptoms of the pulmonary embolism are nonspecific. Laboratory findings have a low diagnostic specificity and chest radiograph is generally nondiagnostic. Scores derived from explicit prediction rules that combine clinical findings at presentation with predisposing factors (table 2) have proved useful in determining the clinical or pretest probability of pulmonary embolism. The Wells score [9], Geneva score [10], and revised Geneva score [11] have been recommended as diagnostic criteria [12]. Our patient 
experienced only a slight tightness of the chest before admission, and her physical examination on admission produced no findings suggestive of pulmonary embolism. Laboratory findings revealed slight leukocytosis, elevated levels of lactate dehydrogenase, and slight hypoxemia without hypocapnia. The clinical prediction scores for acute pulmonary embolism (table 2 ) indicated a low probability: the Wells score was 0 , the Geneva score 4, and the revised Geneva score 3. Only one of three separate measurements of D-dimer levels by quantitative latex agglutination, a moderately sensitive D-dimer assay, revealed an elevation, and the elevation was slight: $1.23,0.99$, and $0.77 \mu \mathrm{g} / \mathrm{ml}$, respectively (reference range from 0 to $1 \mu \mathrm{g} / \mathrm{ml}$ ). We propose that pulmonary artery sarcomas should be strongly suspected in cases who present with mass lesions in the pulmonary arteries but score low on the clinical prediction indexes and have low D-dimer levels.

We believe that the left pulmonary artery had become occluded gradually over time in this case. Had the occlusion been sudden, the patient would have suffered severe and possibly fatal distress. As it turned out, she complained of few symptoms and manifested no signs of occlusion such as tachypnea, wheezing, or tachycardia. Her electrocardiographic abnormalities, meanwhile, were very trivial. We can presume, therefore, that she adapted to the gentle and quiet progression of the left pulmonary artery occlusion. Pulmonary embolisms usually arise from venous thrombosis, but our patient had no history of thromboembolism, nor signs or symptoms of deep venous thrombosis such as leg pain, warmth, or swelling. She was also free from any risk factors for thromboembolism.

Several indicators on CT and MRI favor the diagnosis of pulmonary artery sarcoma over chronic thromboembolic disease [13]. In contrast to the abrupt vascular narrowing and cutoff in embolic disease, sarcomas form a contiguously soft tissue-filled pulmonary artery, sometimes with vascular distension and extravascular spread. Unilateral central pulmonary embolus is uncommon. Pulmonary artery sarcomas are more likely to have a heterogeneous appearance from areas of necrosis, hemorrhage, and ossification (especially osteosarcoma/chondrosarcoma). Enhancement after gadopentetate dimeglumine in the MRI examination is suggestive of sarcoma instead of thromboembolic disease, which does not enhance.

Most of the nodular shadows in our patient were located proximal to the left lungs on the chest CT. This suggested that the tumor emboli had had a certain amount of volume, had been trapped in the relatively large pulmonary arteries and had invaded the surrounding lung tissues. This was an uncommon chest CT finding for pulmonary thromboembolism, as the nodules were too big for thrombi (thrombi are normally about the same size as the pulmonary arteries). Ito et al. [14] reported that FDG-PET could discriminate pulmonary artery sarcoma from pulmonary embolism based on SUVmax: SUVmax of the pulmonary artery sarcomas was $7.63 \pm 2.21$, whereas the SUVmax of the pulmonary embolisms was $2.31 \pm 0.41$. However, the SUVmax of the tumor in our case was 2.6.

Differential diagnosis also included primary and metastatic lung cancer. Our patient never smoked and her serum tumor markers (CEA, CYFRA, SLX, SCC, NSE, and ProGRP) were all within normal ranges. If the multiple nodules in the left lung were metastases, they probably originated from the left main pulmonary artery. If they had come directly from the general circulation, they would have metastasized to both lungs 
diffusely. It would be unlikely for a cancer of this type to first metastasize to the left main pulmonary artery, grow there, and then metastasize again to the left lung. Moreover, our FDG-PET and other examinations failed to detect any primary cancers capable of developing blood-borne metastasis to the left main pulmonary artery.

We postulate that the actual prevalence of pulmonary artery sarcoma is much higher than the estimated prevalence, as pulmonary artery sarcoma is difficult to diagnose and often goes unidentified without autopsy. The prognosis for patients with pulmonary artery sarcoma is poor. In most series, the mean survival time is less than 2 years. Whether treatments with chemotherapy or radiation therapy affect prognosis is unclear, as randomized trials of these tumors are not available to guide therapy. Radical surgical resection seems to provide the only hope of long-term survival [15].

\section{Conclusion}

Clinicians must be mindful of pulmonary artery sarcoma when making the differential diagnosis for patients with mass lesions in the pulmonary arteries. The clinical prediction scores (Wells score, Geneva score, and revised Geneva score) and the CT findings can help to identify the patients with pulmonary artery sarcoma.

\section{Disclosure Statement}

The authors declare no conflict of interest. 
Table 1. Laboratory tests on admission

\begin{tabular}{|c|c|c|}
\hline & Value & Reference $^{\mathrm{a}}$ \\
\hline \multicolumn{3}{|l|}{ Hematologic examination } \\
\hline White blood cells, $/ \mathrm{mm}^{3}$ & 9,300 & $(3,600-9,300)$ \\
\hline \multicolumn{3}{|l|}{ Differential count, $\%$} \\
\hline Neutrophils & 75.7 & $(41.7-74.1)$ \\
\hline Lymphocytes & 16 & $(18.9-47.7)$ \\
\hline Monocytes & 7.2 & $(3.6-8.5)$ \\
\hline Eosinophils & 0.8 & $(0.6-8.5)$ \\
\hline Basophils & 0.3 & $(0.0-1.5)$ \\
\hline Atypical lymphocytes & 0 & $(0)$ \\
\hline Hemoglobin, g/dl & 12.9 & $(12-15)$ \\
\hline Hematocrit, $\%$ & 38.3 & $(34-45.3)$ \\
\hline Platelet count, $\times 10^{4} / \mathrm{mm}^{3}$ & 18.1 & $(12-41)$ \\
\hline \multicolumn{3}{|l|}{ Chemical constituents of blood } \\
\hline Total protein, g/dl & 6.5 & $(6.6-8.1)$ \\
\hline Albumin, g/dl & 3.7 & $(4.1-4.9)$ \\
\hline Urea nitrogen, mg/dl & 14 & $(7-19)$ \\
\hline Creatinine, $\mathrm{mg} / \mathrm{dl}$ & 0.45 & $(0.7-1.1)$ \\
\hline Sodium, $\mathrm{mmol} / \mathrm{l}$ & 139 & $(138-146)$ \\
\hline Potassium, mmol/l & 4.3 & $(3.7-5.0)$ \\
\hline Chloride, $\mathrm{mmol} / \mathrm{l}$ & 99 & $(99-107)$ \\
\hline Calcium, mg/dl & 9.3 & $(9.2-10.7)$ \\
\hline Lactate dehydrogenase, $\mathrm{U} / \mathrm{l}$ & 249 & $(109-210)$ \\
\hline Alanine aminotransferase, $\mathrm{U} / \mathrm{l}$ & 28 & $(13-35)$ \\
\hline Aspartate aminotransferase, U/l & 19 & $(8-48)$ \\
\hline Alkaline phosphatase, U/l & 335 & $(104-338)$ \\
\hline Bilirubin total, mg/dl & 0.7 & $(0.3-1.2)$ \\
\hline Glucose, $\mathrm{mg} / \mathrm{dl}$ & 72 & $(75-107)$ \\
\hline Creatine kinase, $\mathrm{U} / \mathrm{l}$ & 67 & $(35-175)$ \\
\hline Glycosylated hemoglobin A1c, \% & 4.4 & $(4.3-5.8)$ \\
\hline Soluble IL-2 receptor & 836 & $(220-530)$ \\
\hline Angiotensin-converting enzyme & 10.8 & $(8.3-21.4)$ \\
\hline $\mathrm{KL}-6, \mathrm{U} / \mathrm{l}$ & 162 & $(0-500)$ \\
\hline SP-D, ng/ml & 17.2 & $(0-110)$ \\
\hline$(1 \rightarrow 3)-\beta-D$-glucan, $p g / m l$ & $<6.0$ & $(0-20)$ \\
\hline Cryptococcus antigen & negative & (negative) \\
\hline Candida antigen & negative & (negative) \\
\hline Aspergillus antigen & $0.3^{\circ}$ & $(0-1.0)$ \\
\hline \multicolumn{3}{|l|}{ Serology } \\
\hline C-reactive protein, $\mathrm{mg} / \mathrm{dl}$ & 2.3 & $(\leq 0.3)$ \\
\hline $\mathrm{IgG}, \mathrm{mg} / \mathrm{dl}$ & 975 & $(868-1,780)$ \\
\hline $\mathrm{IgM}, \mathrm{mg} / \mathrm{dl}$ & 50 & $(57-310)$ \\
\hline $\mathrm{IgA}, \mathrm{mg} / \mathrm{dl}$ & 250 & $(122-412)$ \\
\hline Rheumatoid factor, IU/ml & 52 & $(0-20)$ \\
\hline Rheumatoid arthritis particle agglutination, dilution factor & 160 & $(0-40)$ \\
\hline \multicolumn{3}{|l|}{ Tumor markers } \\
\hline Carcinoembolinic antigen, $\mathrm{ng} / \mathrm{ml}$ & 0.5 & $(0-5)$ \\
\hline Cytokeratin fragment $19, \mathrm{ng} / \mathrm{ml}$ & $<1.0$ & $(0-3.5)$ \\
\hline Sialyl Lewis X-i antigen, $\mathrm{U} / \mathrm{ml}$ & 21 & $(0-38)$ \\
\hline Squamous cell carcinoma antigen, $\mathrm{ng} / \mathrm{ml}$ & $<0.5$ & $(0-1.5)$ \\
\hline Neuron-specific $\gamma$-enolase, $\mathrm{ng} / \mathrm{ml}$ & 5.4 & $(0-10)$ \\
\hline Pro-gastrin releasing peptide, $\mathrm{ng} / \mathrm{ml}$ & 14.4 & $(0-46)$ \\
\hline
\end{tabular}


Table 1 (continued)

\begin{tabular}{lcc}
\hline & Value & Reference $^{\mathrm{a}}$ \\
\hline Coagulation & & \\
Protein C, \% & 100 & $(62-131)$ \\
Protein S, \% & 72 & $(60-127)$ \\
Anti-cardiolipin- $\beta 2$-glycoprotein I complex & $\leq 1.2$ & $(0-3.5)$ \\
Brain natriuretic peptide, pg/ml & 45.6 & $(0-18.4)$ \\
Prothrombine time, s & 10.9 & $(9-11)$ \\
International normalized ratio & 1.17 & $(0.9-1.1)$ \\
Activated partial-thromboplastin time, s & 32.5 & $(24.5-39.7)$ \\
D-Dimer, $\mu$ g/ml & 1.23 & $(0-1)$ \\
Antithrombin III, \% & 91.5 & $(80-125)$ \\
\hline Arterial blood gas analysis (room air) & & \\
pH & 7.429 & $(7.35-7.45)$ \\
Partial pressure of oxygen, Torr & 69.3 & $(80-100)$ \\
Partial pressure of carbon dioxide, Torr & 38.4 & $(35-42)$ \\
Base excess, mmol/l & 1.2 & $(-2.0$ to 2.0$)$ \\
\hline
\end{tabular}

${ }^{a}$ Range, number, or negative/positive. 
Table 2. Clinical prediction scores for pulmonary embolism

\begin{tabular}{|c|c|}
\hline \multicolumn{2}{|c|}{ Canadian (Wells) prediction score } \\
\hline \multicolumn{2}{|c|}{ Variable and score } \\
\hline 3.0 & Symptoms and signs of deep vein thrombosis \\
\hline 3.0 & Pulmonary embolism more likely than alternative diagno \\
\hline 1.5 & Heart rate $>100$ beats $/ \mathrm{min}$ \\
\hline 1.5 & Previous deep vein thrombosis or pulmonary embolism \\
\hline 1.5 & Recent immobilization or surgery ( $\leq 4$ weeks) \\
\hline 1.0 & Hemoptysis \\
\hline 1.0 & Cancer \\
\hline \multicolumn{2}{|l|}{ Total score } \\
\hline$<2.0$ & Low probability $(1.3 \%)$ \\
\hline $2.0-6.0$ & Moderate probability $(16.2 \%)$ \\
\hline$>6.0$ & High pretest probability $(37.5 \%)$ \\
\hline \multicolumn{2}{|c|}{ Original Geneva (Wicki) score } \\
\hline \multicolumn{2}{|c|}{ Variable and score } \\
\hline 1 & Age $60-79$ years \\
\hline 2 & Age $\geq 80$ years \\
\hline 2 & Previous deep vein thrombosis or pulmonary embolism \\
\hline 3 & Recent surgery \\
\hline 1 & Heart rate $>100$ beats $/ \mathrm{min}$ \\
\hline 2 & $\mathrm{PaCO}_{2}<36.2 \mathrm{~mm} \mathrm{Hg}(<4.8 \mathrm{kPa})$ \\
\hline 1 & $\mathrm{PaCO}_{2} 36.2-38.9 \mathrm{~mm} \mathrm{Hg}(4.8-5.19 \mathrm{kPa})$ \\
\hline 4 & $\mathrm{PaO}_{2}<48.8 \mathrm{~mm} \mathrm{Hg}(<6.5 \mathrm{kPa})$ \\
\hline 3 & $\mathrm{PaO}_{2} 48.8-59.9 \mathrm{~mm} \mathrm{Hg}(6.5-7.99 \mathrm{kPa})$ \\
\hline 2 & $\mathrm{PaO}_{2} 60-71.2 \mathrm{~mm} \mathrm{Hg}(8.0-9.49 \mathrm{kPa})$ \\
\hline 1 & $\mathrm{PaO}_{2} 71.3-82.4 \mathrm{~mm} \mathrm{Hg}(9.5-10.99)$ \\
\hline 1 & Platelike atelectasis in chest radiograph \\
\hline 1 & Elevation of hemidiaphragm in chest radiograph \\
\hline \multicolumn{2}{|l|}{ Total score } \\
\hline$<5$ & Low probability $(10 \%)$ \\
\hline $5-8$ & Moderate probability $(38 \%)$ \\
\hline$>8$ & High probability $(81 \%)$ \\
\hline \multicolumn{2}{|c|}{ Revised Geneva score } \\
\hline \multicolumn{2}{|c|}{ Variable and score } \\
\hline 1 & Age $>65$ years \\
\hline 3 & Previous deep vein thrombosis or pulmonary embolism \\
\hline 2 & Surgery or lower limb fracture in previous weeks \\
\hline 2 & Active cancer \\
\hline 3 & Unilateral lower limb pain \\
\hline 2 & Hemoptysis \\
\hline \multicolumn{2}{|l|}{ Total score } \\
\hline$<4$ & Low probability $(8 \%)$ \\
\hline $4-10$ & Moderate probability $(28 \%)$ \\
\hline$>10$ & High probability $(74 \%)$ \\
\hline
\end{tabular}



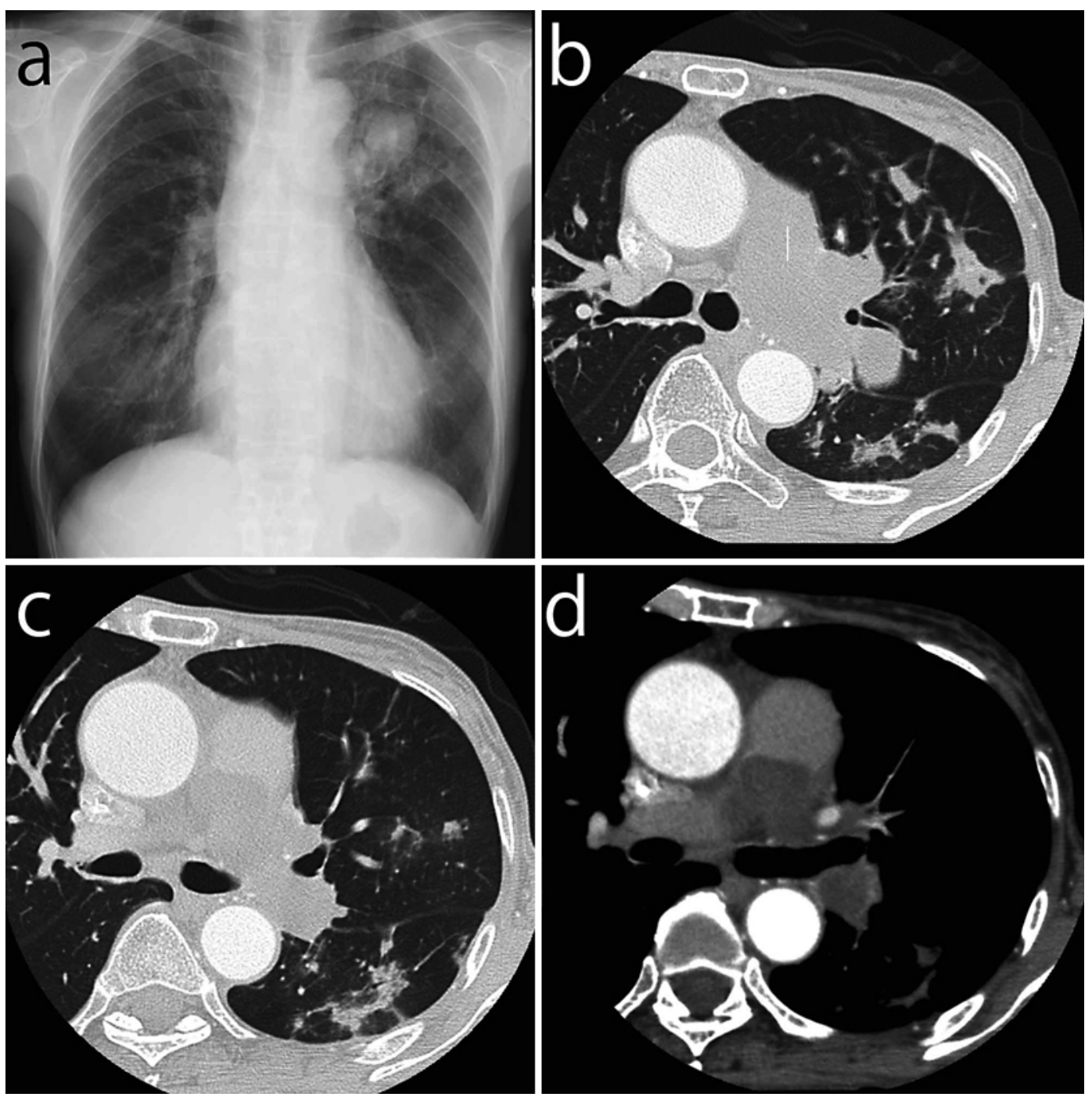

Fig. 1. Chest radiography shows a mass in the left upper lung field (a). CT scans of the chest reveal multiple nodules in left lung $(\mathbf{b}, \mathbf{c})$ and low-density lesions occupying the pulmonary artery $(\mathbf{d})$. 

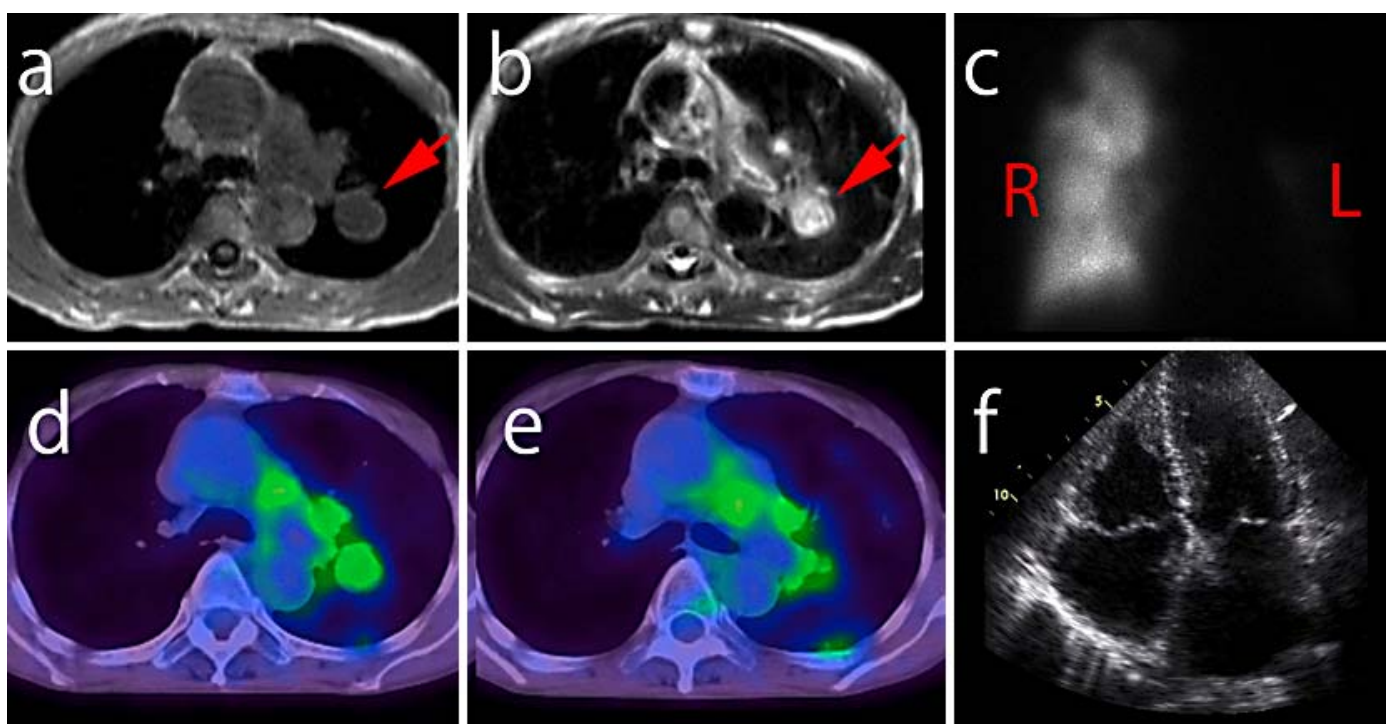

Fig. 2. MRI reveals mass lesions spreading across the pulmonary arteries in the left upper lobe. The lesions have a low-density appearance in the T1-weighted image (a) and a high-density appearance in the T2-weighted image (b). Lung perfusion scintigraphy reveals a perfusion defect in the left whole lung and a focal perfusion defect in the right lung (c). FDG-PET shows multiple mass lesions in the lung fields and mediastinum (d, e) with a SUVmax of 2.6. Transthoracic echocardiography shows pulmonary hypertension with dilation of the left atrium, right atrium, and right ventricle, and concentric left ventricular hypertrophy (f). 

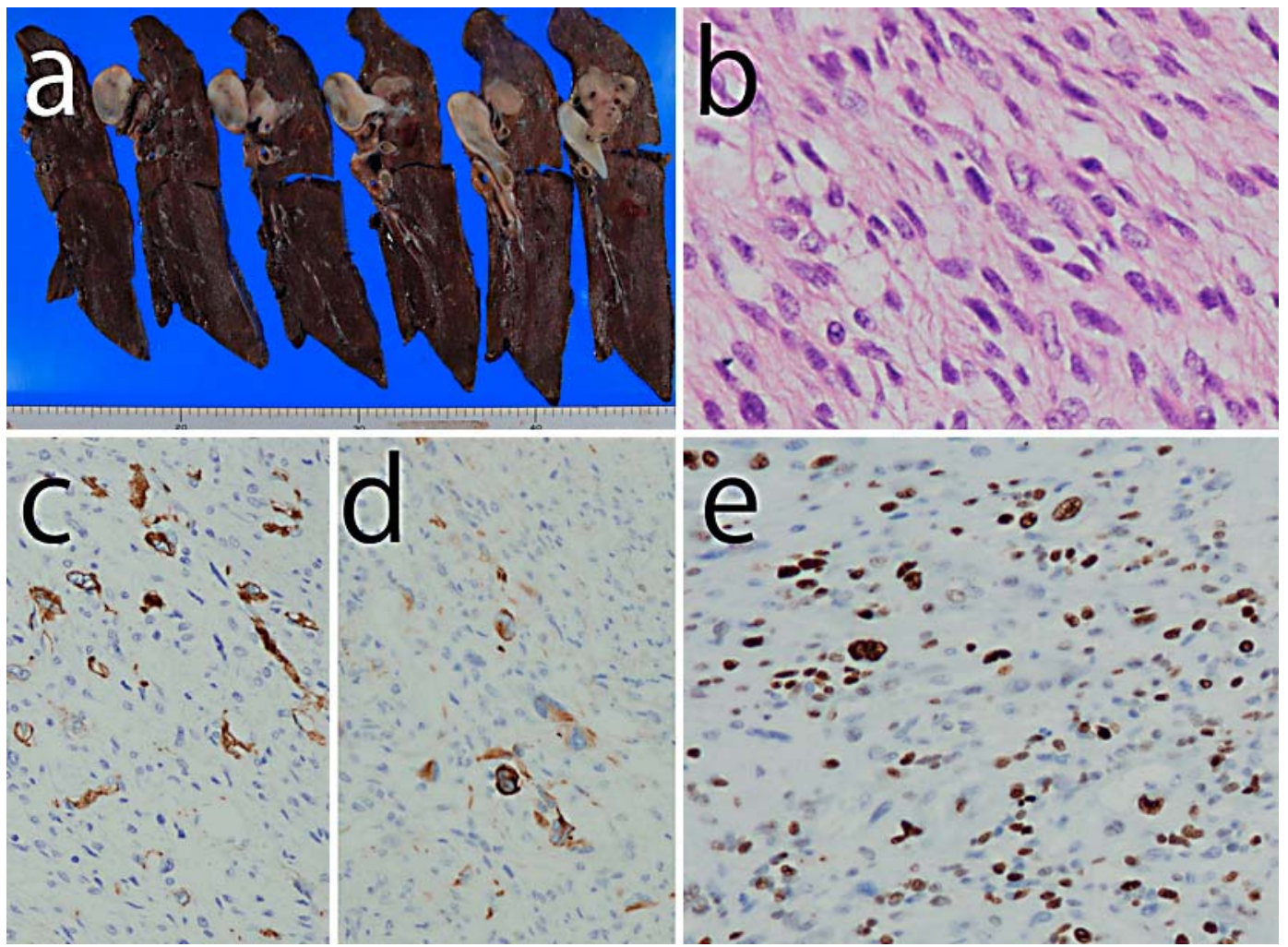

Fig. 3. Gross section shows a clear, ivory-white tumor with necrosis and hemorrhage (a). The left pulmonary artery is dilated to a width of $2.5 \mathrm{~cm}$ by an intraluminal tumor $(6.5 \times 2.5 \times 2.5 \mathrm{~cm})$ extending through the pulmonary arteries into the distal lung parenchyma. The tumor is composed of spindle- or circular-shaped cells with cigar-shaped nuclei and elongated cytoplasm (b). Immunohistochemical stainings for a-SMA (c) and desmin (d) are focally positive. Immunohistochemical staining for the Ki67 labeling index (the percentage of positive cells stained with proliferation marker Ki-67 antibody) is $40 \%(\mathbf{e})$.

\section{References}

1 Huo L, Moran CA, Fuller GN, Gladish G, Suster S: Pulmonary artery sarcoma: a clinicopathologic and immunohistochemical study of 12 cases. Am J Clin Pathol 2006;125:419-424.

2 Bleisch VR, Kraus FT: Polypoid sarcoma of the pulmonary trunk: analysis of the literature and report of a case with leptomeric organelles and ultrastructural features of rhabdomyosarcoma. Cancer 1980;46:314-324.

3 Johansson L, Carlén B: Sarcoma of the pulmonary artery: report of four cases with electron microscopic and immunohistochemical examinations, and review of the literature. Virchows Arch 1994;424:217-224.

-4 Iwasaki H, Isayama T, Johzaki H, Kikichi M: Malignant fibrous histiocytoma. Evidence of perivascular mesenchymal cell origin. Immunocytochemical studies with monoclonal anti-MFH antibodies. Am J Pathol 1987;128:528-537.

5 Evans HL, Shipley J: Leiomyosarcoma; in Fletcher CDM, Unni KK, Mertens F (eds): Pathology and Genetics of Tumours of Soft Tissue and Bone. Lyon, IARC Press, 2002, pp 131-134. Available from: http://www.iarc.fr/en/publications/pdfs-online/pat-gen/bb10/.

6 Bode-Lesniewska B, Komminoth P: Intimal sarcoma; in Fletcher CDM, Unni KK, Mertens F (eds): Pathology and Genetics of Tumours of Soft Tissue and Bone. Lyon, IARC Press, 2002, pp 223-224. Available from: http://www.iarc.fr/en/publications/pdfs-online/pat-gen/bb10/.

7 Baker PB, Goodwin RA: Pulmonary artery sarcomas: a review and report of a case Arch Pathol Lab Med 1985;109:35-39. 
8 Coli A, Parente P, Bigotti G: Pulmonary artery sarcoma: an insidious tumor still diagnosed too late. Analysis of the literature and report of a case. J Exp Clin Cancer Res 2007;26:151-156.

-9 Wells PS, Anderson DR, Rodger M, Stiell I, Dreyer JF, Barnes D, Forgie M, Kovacs G, Ward J, Kovacs MJ Excluding pulmonary embolism at the bedside without diagnostic imaging: management of patients with suspected pulmonary embolism presenting to the emergency department by using a simple clinical model and D-dimer. Ann Intern Med 2001;135:98-107.

10 Wicki J, Perneger TV, Junod AF, Bounameaux H, Perrier A: Assessing clinical probability of pulmonary embolism in the emergency ward: a simple score. Arch Intern Med 2001;161:92-97.

$\checkmark 11$ Le Gal G, Righini M, Roy PM, Sanchez O, Aujesky D, Bounameaux H, Perrier A: Prediction of pulmonary embolism in the emergency department: the revised Geneva score. Ann Intern Med 2006;144:165-171.

12 Meyer G, Roy PM, Gilberg S, Perrier A: Pulmonary embolism. BMJ 2010;340:c1421.

$\checkmark 13$ Kauczor HU, Schwickert HC, Mayer E, Kersjes W, Moll R, Schweden F: Pulmonary artery sarcoma mimicking chronic thromboembolic disease: computed tomography and magnetic resonance imaging findings. Cardiovasc Intervent Radiol 1994;17:185-189.

14 Ito K, Kubota K, Morooka M, Shida Y, Hasuo K, Endo H, Matsuda H: Diagnostic usefulness of 18F-FDG PET/CT in the differentiation of pulmonary artery sarcoma and pulmonary embolism. Ann Nucl Med 2009;23:671-676.

15 Mattoo A, Fedullo PF, Kapelanski D, Ilowite JS: Pulmonary artery sarcoma: a case report of surgical cure and 5-year follow-up. Chest 2002;122:745-747. 